\title{
Algumas Considerações sobre Política Tributária, Sistema Tributário e Administração Tributária
}

\author{
ALFREDO J. LAMAGRANGE * \\ Tradução de Aluizio P. Valle \\ Fonte: "Boletin de la Dirección General Impositiva", fev. 1971, \\ Buenos Aires, República Argentina
}

INTRODUÇAOO

O desenvolvimento econômico crescente e o incremento dos niveis da receita no qual estão empenhados todos os paises da América Latina, ao conseguir-se aquele, incidirá na administração tributária e complicará o trabalho desta em decorrência do aumento do númiero de contribuintes, em razão do aumento da riqueza da população. Desenvolvimento econômico implica em incremento do nivel da receita, maior e melhor distribuição da riqueza, maior número de contribuintes, bem como mais tarefas delicadas e complexas para a administração tributária.

Estas preocupações tomaram forma, em agosto de 1961, ao firmar-se a CARTA DE PUNTA DEL ESTE, estabelecendo o objetivo, na respectiva "De- claração aos Povos da América" de "Reformar as leis tributárias para exigir mais de quem tem mais, castigar severamente a evasão de impostos, redistribuir a renda nacional pelas familias dos setores mais necessitados e, ao mesmo tempo, estimular a inversão e reinversão de capitais e a poupança".1 A meta principal, ao atenuar-se a evasão fiscal e tender-se para sua eliminação, é o incremento da arrecadação, dada a importância que ela tem para qualquer política fiscal que se projete. Portanto, a melhoria da eficiência geral da administração tributária será proporcionada pelo aprimoramento da arrecadação. Para que esta seja satisfatória, torna-se ne-

1. "A CARTA DE PUNTA DEL ESTE". FOtheto. Departamento de Informaçăo Pública. Uniăo Panamericana - Washington, D. C.. Secretaria Geral da OEA. Programas autor deste trabalho, Dr. Alfredo Julio Lamagrange, é o chefe do Departamento de
o Normas de Fiscalizaçăo da DGI. 
cessário controlar ao máximo a evasão. É útil destacar que a evolução fiscal, na prática, "está em grande parte sujeita aos meios técnicos da arrecadação e à eficiência e integridade da administração pública".2

A situação pela qual se manifesta o processo tributário em geral compreende a seguinte trilogia: política tributária, sistema tributário e administração tributária.

\section{POLITICA TRIBUTÁRIA}

Num critério amplo, a política tributária integra-se na politica fiscal, esta por sua vez na política econômica e esta última na política geral propriamente dita. É necessário, em conseqüência, que fixemos critérios no que so refere à conceituação de tais idéias a fim de alcançarmos um esquema não tão generalizado das mesmas. Todas as politicas citadas possuem ou devem possuir um conteúdo evidentemente normativo que se sintetiza quando ao "ser" juntamos o "deve ser".

Interessa a nossos objetivos a concepção da política como ação ou conduta de governo, desenvolvida como governo no sentido mais estrito. Ou seja, política no sentido arquitetônico, - que acaba sendo a concepção mais antiga do termo e que vê nela o comportamento humano de chefes, governantes ou estadistas na fundação, organização ou direção da "polis". A esse respeito nos ilustra ORTEGA Y
GASSET, expressando que "Política é
ter idéia clara do que ter idéia clara do que se deve fazer com a Naçăo, a partir do Estado".

A politica econômica tende a harmonizar, dentro dos fins traçados pe- las economias do setor privado e público que vivem em uma espécie de simbiose, o alcance dos objetivos comuns, de acordo com as decisões tomadas em razão dos valores prioritários que fixem, num momento histórico determinado, os encargos de inspirála. Isto não significa independência total das duas economias mas, ao contrário, harmonização, e a política fiscal deve adequar seus instrumentos volume dos gastos, flexibilidade do tributo etc. - de acordo com a realidade econômica que se queira aplicar.

A politica fiscal define-se como a que "se ocupa da planificação eficaz das rendas e dos gastos públicos, especialmente no que diz respeito ao seu volume global, a fim de lograr-se variaçōes favoráveis no nivel geral da receita, dos preços e do emprego". 3

Cabe destacar que, com respeito aos países não desenvolvidos, a política fiscal tem como propósito fundamental a formação da poupança pública destinada a financiar a inversão pública exigida pelo mesmo desenvolvimento econômico, influir na taxa e na estrutura da inversão e no consumo privados, de forma congruente com as metas globais e direcionais de desenvolvimento. Ademais, tem como objetivo assegurar ao Estado os recursos necessários para o atendimento de seus gastos correntes.

2. DESAI, Rajanikant, "A Capacidade Fiscal dos Paises em Desenvolvimento: Questóes de Política Tributária": Em Reforma Tributa de ria para a América Latina: II. Prablemas nfePolitica Fiscal. Documentos e Atas da COArência de Santiago do Chile, dez. 1962. OEA 96, BID-CEPAL-Uniăo Panamericana, pág. 1964.

3. Henry C. MURPHY em "Que significa realmente Politica Fiscal", "Rev. Finanzas Y Desarrollo". Vol. 7 - N.0 2 - Junho, 1970 Págs. $15 / 22$, 
Com relação aos propósitos da politica fiscal e da tributação, JARACH 4 traça o seguinte esquema, colocando ênfase em que a finalidade primordial da política fiscal é estruturar a economia do setor público de maneira congruente com os fins que se the atribuam, como um sistema de economia diferente da economia de mercado ou setor privado. Para alcançar isto, a política fiscal deve:

1. adequar os instrumentos arrecadadores aos critérios de justiça ou eqüidade predominantes em cada país e no momento histórico;

2. influir na distribuição ou redistribuição da renda nacional e promover "a subdivisão de determinadas formas patrimoniais ou a modificação das reformas de propriedade...";

3. evitar as situaçöes conjunturais da economia que indiquem uma política de estabilização;

4. promover o desenvolvimento ou crescimento econômico do país.

Se aceitamos o imposto como um fenômeno econômico-financeiro cuja substância é econômica e cujo nascimento institucional deve caracterizarse juridicamente por meio da lei, compreenderemos então a importância do sistema tributário e a repercussão que terá sobre a administração tributária traçar-se uma política de impostos através do dito sistema.

\section{SISTEMA TRIEUTARIO} Julgamos que um sistema tributário
será ou deverá tender para ser, técnica e administrativamente, um conjunto orgânico de impostos que se harmonizem entre si e ao mesmo tempo com os objetivos da política tributária que se determine. A citada harmonia deve ser intencional por parte do legislador, cercada da máxima racionalidade que assegure a satisfação das necessidades púb!icas - gastos e inversões tendo em consideração ao mesmo tempo todos os princípios fundamentais da imposição. REIG expressa que "em matéria tributária se deveria chamar sistema tributário a um conjunto harmônico de tributos que se nutrem em princípios econômicos e políticos adequados a um meio econômico e social dados". 5

Um sistema tributário deficiente é uma das causas fundamentais da evasão fiscal e sua estrutura tem implicações econômicas indesejáveis, destorce o sistema de preços e se torna também ineficiente, em função do rendimento da receita pública. Tal deficiência limita ainda o desenvolvimento de uma politica fiscal que deveria servir de instrumento de estímulo ou desestimulo para certas atividades econômicas. Se o sistema tributário tem pouca influência no setor privado, as decisões de inverter ou desinverter não o levam em consideração.

Se aceitarmos, com SCHMOLDER, que o conceito de sistema tributário implica em certa harmonia dos diversos impostos entre si e com os objetivos da imposiçăo fiscal ou não fiscal e se aquela é conseguida por expressa intenção do legislador, encontramo-nos ante um sistema de impostos denominado racional, isto indicando que os

4. Dino JARACH. "Impuesto sobre el Patrimonio y las sucesiones y donaciones". Comunicaçăo apresentada à Conf. de Politica Fiscal para o Desenvolvimento Económico da A m ér l c a Latina. OEA-BID-CEPAL-Chile, 1962.

5. REIG, Enrique. "Sistemática Tributária", Anais da Associação. Argentina de Direito Fiscal. Biênio 1968-1969 - Pág. 88. 
tributos que o compõem perseguem fins políticos sustentados em uma séria teoria tributária. Se a consecução da dita harmonia é obtida por evolução histórica da sanção de diversos tributos e pela modificação periódica dos mesmos, encontramo-nos ante um tipo de sistema tributário denominado histórico.

Esta última concepção pareceria adequar-se ao caso argentino, no plano nacional. Modifica-se o sistema dentro de um esquema básico, composto pelos impostos tradicionais, periodicamente - anualmente - , sem que tais alterações signifiquem mudanças profundas que configurem uma verdadeira reforma tributária. Tais modificações só têm contido, em geral, mudanças de incremento ou marginais.

Entretanto pareceria lógico pensarse que do ponto de vista técnico tributário não existiria contradição alguma entre os sistemas racionais $e$ os sistemas históricos, concordando-se com HEGEL em que a razão é o princípio da realidade, ou seja que o real é racional e o racional é real porque não há posição real - sistema tributário histórico - que não tenha sua justificação racional.

\section{ADMINISTRAÇAO TRIBUTARIA, CONCEITO E OBJETO}

Analisaremos, primeiramente, algumas opiniöes. Um conceito aproximado surge do debate sobre o trabalho de CROCKETT, "Obstáculos gerais para uma eficiente administração de imposto", 6 do qual se aproveita a participação dos funcionários que se desempenham na administração fiscal, na elaboração de normas tributárias. Considera-se que os técnicos que confeccionam as leis de impostos desco- nhecem, em muitas oportunidades, as difículdades reais da arrecadaçăo, apesar de que o sistema tributário possa ser considerado "excelente", e que tais especialistas só têm em mira:

a) cobrar o máximo;

b) reduzir ao minimo o custo e 0 tempo dos serviços de arrecadação;

c) assegurar 0 estrito cumprimento da Lei de Imposto.

Esta concepção deixa entrever que existem outros fins que preocupam todo organismo tributário, não considerados pelos encarregados de formular tais normas. A este respeito opina Marius FARIOLETTI 7 que "o objetivo da Administração Tributária é a cabal aplicação do sistema tributário". Esta concepção é mais ampla que a anterior e sem dúvida mais completa. Em algumas oportunidades todo sistema tributário prevê cerios atos que não implicam somente nos enumerados anteriormente. Distingue este autor como propósitos visados por tal instituiçẫo:

- A longo prazo: Elevar ao máximo as rendas arrecadáveis legalmente, por conceito de imposto, com o mintmo custo.

- A curto prazo: Elevar ao máximo as rendas arrecadáveis com os recursos que o governo põe à disposiçăo do serviço administrativo.

Wilhelm GERLOFF, 8 referindo-se aे principal tarefa da administração tri-

6. CROCKETT, Joseph "Obstáculos Gene" imuna eficiente administración de 61 -
Conf. Buenos Aires - out. 61 .

EA-BID-CEPAL. Discussăo: Pág. 19. Esta7. FARIOLETTI, Marius. "Información Edmidistica para el control y manejo de la 97. nistración Tributaria". Conf. cit. pág. 97. 8. GERLOFF, Wilheim. "Doctrina de la EC nomia Tributaria'". No ponto 1, pág. 262 úblicas" Tomo $d 1$ do "Tratado de Finanzas Púbilcas" EL de GERLOFF $Y$ NEUMARK, 2 tomos - It: ATENEO - Buenos Aires, 1961 - Tomo 823 páginas. (Pág. 197/300.) 
butária - a arrecadação de impostos - considera que procura atingir a três objetivos:

a) que se realiza em beneficio de toda a comunidade a fim de que o Estado obtenha os recursos necessários para alcançar os objetivos previstos;

b) que 0 Estado tem interesse em que tenha êxito. Tal acontecimento demonstra a exatidão e pouca complexidade do direito impositivo. O que significa que a arrecadação, cuja fonte é o sistema tributário, seria um reflexo da efetividade deste;

c) que também se trata de amparar o interesse do contribuinte, ao ficar devidamente protegido contra toda arbitrariedade fiscal quando cumpre suas obrigações tributárias.

As idéias precedentes procuram inCluir na noção de arrecadação de impostos outras funções especificas de um organismo arrecadador. Existem opiniōes no sentido de que a administração tributária deve participar ativamente na formulação da política tributária. Assim sendo, alguns propósitos do organismo arrecadador, citados anteriormente, deixariam de lado o conceito de "política", tão importante quanto o de "administração". Precisamente ao nível de Administração podem surgir inconvenientes se a legislação não estabelece perfeitamente os limites de tais funçöes, sentindo-se o administrador tributário em dificuldades, algumas vezes, por ter de exeCutar uma política na qual ele não Participou ou não foi consultado. A situação pode agravar-se quando se proCura implantar uma reforma tributária de tal magnitude que o organismo arrecadador não esteja habilitado para administrá-la em conjunto. John DUE escreve: 9 "Nenhum imposto pode harmonizar-se com padrões aceitáveis de eqüidade se não é possível administrá-lo com um alto grau de eficiência".

Considera LINDHOLM 10 que se a administração tributária é de alta eficiência a capacidade do sistema tributário materializa-se ao atingir os objetivos que se tiverem em conta ao estruturá-lo e sancionar-se sua vigência, de conformidade com a política fiscal traçada.

Distinguimos então duas funçð̌es completamente diferentes. $\mathrm{Na}$ medlda da eficiência de uma delas - administração de impostos - são alcançados os fins da outra - política fiscal. Esta última visa obter, segundo LINDHOLM, "um correto nível de preços, consumo, emprego e distribuição da renda". Tais niveis seriam afetados por uma atividade fiscal deficiente, expressada por suposição através da despeza ou inversão pública, cujos frutos não se manifestam para o contribuinte como verdadeiros benefícios externos.

Se bem que possamos diferençar os problemas de ambas as esferas, onde aparentemente as questóes da política tributária ficam fora do alcance da administração tributária, isto nem sempre é tăo simples. Em algumas oportunidades, medidas de caráter técnico impostas em nivel administrativo pelo organismo arrecadador, com o objetivo de assegurar-se o recebimento dos tri-

9. DUE, John F. "Análises Económico de los Impuestos". 1. " Ediçấo, El Ateneo Buonos Aires, 1961 - Pâg. 548 (Capltulo 8 - págs. 141 e seguintes).

10. LINDHOLM, Richar W. "Introducción a la Politica Fiscal". Rev. de Ocidente S.A. Madri, 1958 - 287 págs. - La Administración de Impuestos - pág. 248. 
butos, podem influir sobre a conduta dos contribuintes e não combinar com o objetivo que uma determinada politica pode ter traçado. Por exemplo, a adoção de uma medida esclarecedora sobre informação que os bancos oficiais devem prestar nos casos em que o organismo arrecadador o solicite, pode influir para que os depositantes retirem seus saldos em tais instituições e busquem outros bancos privados. Isto interromperia o desenvolvimento das entidades financeiras de tal ca-
ráter.

De acordo com o enunciado, podemos descrever a Administração Tributária como um sistema administrativo destinado à justa aplicação de um regime tributário consentâneo com uma determinada política fiscal. Em síntese, a administração tributária acaba sendo um instrumento da política fiscal.

O conceito emitido não implica na elaboração de uma definição. Não pretende ser rígido; trata-se de uma aproximação conceitual para tal atividade. Se recordamos, além disto, que uma administração de impostos eficaz deve ter condições para facilitar informação para os responsáveis pela elaboração da política tributária, deduz-se que seu trabalho não se reveste de um caráter meramente passivo. Sobre a exequibilidade de se administrar o sistema, fazse necessária a opinião do administrador tributário na formulação da politica de impostos. A opinião dos responsáveis pela direção da administração tributária deve ser observada quando se sugerem modificaçöes para a melhor fiscalização e recebimento
dos tributos.

A concepção citada sobre administração de impostos procura introduzir certos limites entre os setores mencionados, devendo-se destacar que seja aplicada pelo organismo arrecadador, refere-se à interpretação de uma lei tributária ou a um método administrativo para assegurar-se o recebimento do imposto, deverá ser compativel com a política fiscal que trace o nivel correspondente e ajustar-se à mesma, procurando interpretar os objetivos que - legislador pretendeu alcançar com a citada norma.

\section{1 - A ADMINISTRAÇÃO TRIBUTÁRIA E SUAS ÁREAS PRINCIPAIS}

É interessante destacar que em toda estrutura de organização pode-se distinguir três áreas perfeitamente diferenciadas:

- Área planificadora, assessora e implementadora de recursos materiais e humanos.

- Área executiva ou operativa, que deve levar a cabo, de forma coordenada, a ação que Ihe determinar o setor citado precedentemente.

- Área de avaliação e controle do trabalho que realiza principalmente o setor operativo $e$, em alguns casos, o setor planificador e implementador.

$\mathrm{Na}$ administração de impostos, a área operativa compreende a área de execução da lei tributária. Nela se reflete perfeitamente a relação fisco-contribuinte, quer se trate da cobrança do tributo (arrecadação) ou da determinação da verdadeira situação relativa a impostos dos sujeitos passivos da relação tributária (fiscalização).

Do ponto de vista da organização $e$ administração de um organismo tribu- 
tário distinguem-se as atividades de arrecadação e execução da lei, entendendo-se por esta última unicamente a função de fiscalização. "A execução de uma lei compreende os procedimentos para a descoberta das fraudes, assim como dos erros de boa-fé. A execução da lei relaciona-se com todas as técnicas destinadas a elevar o nivel do cumprimento voluntário, por parte do contribuinte, assim como as que têm por objetivo assegurar que os contribuintes tenham realmente pago o valor correto do imposto". 11

Com respeito à área da arrecadação, deu-se uma interpretação mais ampla de suas funções e elas abarcariam "desde a individualização do contribuinte, controle dos aspectos formais de sua obrigação fiscal, até o cancela- mento de sua divida com o fisco". Em celação com a área de Fiscalização conceituou-se como a "função de determinar-se o imposto declarado pelo contribuinte está de acordo com a norma legal". $12 \mathrm{Em}$ outras palavras, fiscalização subentende o conjunto de procedimentos que têm por finalidade verificar se o imposto pago pelo contribuinte é o que corresponde à realidade dos fatos econômicos sujeitos a tributação.

A função específica da administração de impostos é dada pela área de operatividade que possua maior proporção de pessoal (mais de $75 \%$ ) e nesta é onde o contribuinte sente seu zontato com o fisco, como se pode observar no seguinte quadro:

QUADRO I

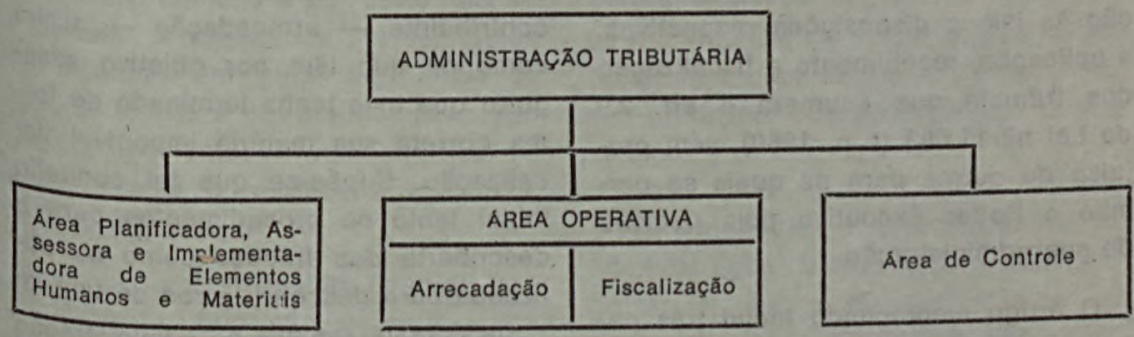

Como se poderá observar no quadro precedente, tanto a DGI quanto o IRS possuem maior proporção de pessoal lotado na área operativa - mais de $75 \%$. Em "Outras Áreas" incluiu-se o pessoal dos setores de assessoramento, de controle e mais o que integra a dotação do Sistema de Processamento de Dados. O citado processamento pode chegar a uma importante poupança de força de trabalho na área operativa, no que se refere ao forne- cimento de informação múltipla dos contribuintes, com especial destino ao setor fiscalizador. Qualquer programa de auditoria tributária para ter êxito deverá ser alimentado por um sistema de informação que guie o agente fiscalizador no sentido de cumprir o seu encargo.

11. Veja-se "Manual de Administración del Impuesto de Renda" do Programa Internacional de Tributaçäo da Escola de Leis da Uni. versidade de Harvard. Reproduçăo "Borrador" CICAP (1967). 


\section{QUADRO II}

Proporção do Pessoal da "Dirección General Impositiva" (Rep. Arg.) e do "Internal Revenue Service" (USA) lotado no Setor Operativo

\begin{tabular}{|c|c|c|c|c|}
\hline \multirow{2}{*}{ Localizaçăo } & \multicolumn{2}{|c|}{ IRS } & \multicolumn{2}{|c|}{ DGI } \\
\hline & 1967 & $\%$ & 1970 & $\%$ \\
\hline Total da repartição .. & 65.122 & 100 & 7.307 & 100 \\
\hline Area operativa & 50.321 & 77,27 & 5.562 & 76,11 \\
\hline $\begin{array}{l}\text { a) Arrecadaçäo } \ldots \ldots \ldots \ldots \\
\text { b) Fiscalização } \ldots \ldots \ldots \ldots \ldots \\
\text { c) Outros setores operativos }\end{array}$ & $\begin{array}{c}29.497 \\
20.824 \\
-\end{array}$ & $\begin{array}{r}45,29 \\
31,98 \\
-\end{array}$ & $\begin{array}{l}2.049 \\
1.785 \\
1.728\end{array}$ & $\begin{array}{l}28,05 \\
24,46 \\
23,60\end{array}$ \\
\hline Outras áreas & 14.801 & 22,73 & 1.745 & 23,89 \\
\hline
\end{tabular}

Em noso pais, a "Dirección General Impositiva", 12 criada pela Lei número 12.927 , tem a seu cargo, em sujeição às leis e disposições respectivas, a aplicação, recebimento e fiscalização dos tributos que enumera 0 art. $2 .^{\circ}$ da Lei $n$ \% 11.683 (t. o. 1960), sem prejuízo de outros para os quais se permite o Poder Executivo pela decisão de sua administração.

0 artigo mencionado inclui três palavras que compreendem conceitos aparentemente distintos. No entanto, o conteúdo da palavra aplicação é mais amplo do que os outros dois restantes e, segundo nosso critério. poderia inclui-los. O legislador talvez houvesse esquecido os termos recebimento e fiscalização, pois estariam implicitamente compreendidos no vocábulo aplicação. Tal palavra implica, entre outros conceitos, na execução da lei de impostos, levada a cabo por procedimentos que the são próprios para se conseguir um determinado fim. Compreende as técnicas destinadas a elevar o nivel do cumprimento voluntário por parte do contribuinte - arrecadação - assim como os que têm por objetivo assegurar qua este tenha terminado de forma correta sua matéria imponivel fiscalização. Supõe-se que tal conceito inclui tanto os procedimentos para a Cescoberta das fraudes como os utilizados para descobrir erros de boa-fé.

No modelo simples de administraçăo tributária esquematizado, temos destacado a função de fiscalização que tem como atividade especial verificar a relação imposto potencial-imposto declarado. A diferença entre estes dois conceitos delinela uma das brechas ${ }^{13}$

Pedro F. "Bases para un modelo de sistema fiscal de recaudación interna". Boletin Dirección General Impositiva Buenos Aires - Mapúb 1968, págs. $440 / 41$.

F. $=$ cit. Em seu 13. PAVESI, Pedro F. $=$ ob. cit. Em contri-
modelo as três brechas restantes săo: con conbuinte potencial $X$ contribuinte registrado; apretribuinte individualizado $X$ contribuinte pago. sentado; imposto declarado $X$ imposto 
de evasão. Seu ataque é tipicamente recurso da área citada e o mesmo requer atitudes de uma elite de pessoal fiscalizador convenientemente adestrado. É evidente que estes conceitos excluem a cibernética, como elemento fundamental do trabalho de fiscalização, o qual deverá servir de apoio logístico, mas não poderá substituir a habilitação de elementos humanos de alto nivel.

\section{CONCLUSAO}

No presente trabalho ficou demonstrada a significativa relação e interdependência existente na trilogia: politica, sistema e administração tributárias.

No que se refere a sistema tributário, não nos parece tão aceitável a distinção entre sistema histórico e sistema racional. As diferenças não seriam tão profundas e por certo não resultariam contraditórias, revestindo-se os sistemas em geral de ambas as características e, em muitos casos, são usados elementos irracionais que se ajustam a uma verdadeira anti-sistemática tributária.

Deixou-se estabelecido, contudo, explicitamente, que não cabe à administração tributária traçar a politica de impostos, dando-se ênfase especial a que a função daquela não se reveste em tal contexto de um caráter meramente passivo. O organismo arrecadador e fiscalizador, em nossa opinião, deveria participar da elaboração de tal politica, em nivel de consulta permanente. Ele se encontra em pleno contato com a realidade econômica na qual repousa o imposto e, a este resPeito, não só pode ministrar valiosíssimas informações sobre o comporta- mento e efeitos de cada um dos tributos que compõem o sistema que administra mas também oferecer a experiência acumulada em sua função especifica de interpretar as disposiçōes das leis "que estabelecem ou regem o recebimento dos gravames a seu cargo" (art. 8 ?, Lei n? 11.683 , t. o. 1968). Neste sentido, a consulta se materializaria em anteprojetos de modificação do sistema que deveria adequarse às pautas políticas que the forem ditadas com a devida antecipação. É bem possivel que, neste aspecto, a administração de impostos, interpretando os delineamentos que the forem traçados, assim como a intenção do legislador, nas disposições que tenham vigência, em seus anteprojetos, contribua para aperfeiçoar as normas e fechar as brechas de evasão que em algumas oportunidades se produzem por dificuldades de técnica legislativa ou por vigência de disposições que não puderam prever certos fenômenos que se produzem posteriormente a sua sanção.

Ao conceituar-se a conformação da administração tributária em geral, a grosso modo, e ao comparar-se as principais áreas, tendo em vista suas funções especificas, assim como o material humano que as desenvolve, podese concluir que tal administração é um órgão eminentemente operativo, com atribuições perfeitamente delimitadas. $\mathrm{Na}$ Dirección General Impositiva (Rep. Arg.) e no Internal Revenue Service (USA) manifesta-se uma distribuição de elementos humanos em quantidade de relativa semelhança, absorvendo a área essencialmente operativa a maior parte de seu pessoal. 